\title{
BMJ Open Characteristics of registered clinical trials assessing treatments for COVID-19: a cross-sectional analysis
}

\author{
Hemalkumar B Mehta (D) , ${ }^{1,2}$ Stephan Ehrhardt, ${ }^{1}$ Thomas J Moore (i) , ${ }^{3}$ \\ Jodi B Segal, ${ }^{1,2,4}$ G Caleb Alexander ${ }^{1,2}$
}

To cite: Mehta HB, Ehrhardt S, Moore TJ, et al. Characteristics of registered clinical trials assessing treatments for COVID-19: a cross-sectional analysis. BMJ Open 2020;10:e039978. doi:10.1136/ bmjopen-2020-039978

- Prepublication history and additional material for this paper are available online. To view these files, please visit the journal online (http://dx.doi. org/10.1136/bmjopen-2020039978).

Received 01 May 2020

Revised 11 May 2020

Accepted 12 May 2020

\section{Check for updates}

(c) Author(s) (or their employer(s)) 2020. Re-use permitted under CC BY-NC. No commercial re-use. See rights and permissions. Published by BMJ.

${ }^{1}$ Department of Epidemiology, Johns Hopkins University Bloomberg School of Public Health, Baltimore, Maryland, USA

${ }^{2}$ Center for Drug Safety and Effectiveness, Johns Hopkins Bloomberg School of Public Health, Baltimore, Maryland, USA

${ }^{3}$ Institute for Safe Medication Practices, Alexandria, Virginia, USA

${ }^{4}$ Department of Health Policy and Management, Johns Hopkins Bloomberg School of Public health, Baltimore, Maryland, USA

Correspondence to Dr G Caleb Alexander; galexan9@jhmi.edu

\section{ABSTRACT}

Objectives The coronavirus disease 2019 (COVID-19)

pandemic has prompted many initiatives to identify safe and efficacious treatments, yet little is known regarding where early efforts have focused. We aimed to characterise registered clinical trials assessing drugs or plasma treatments for COVID-19.

Design, setting and participants Cross-sectional analysis of clinical trials for the treatment of COVID-19 that were registered in the USA or in countries contributing to the WHO's International Clinical Trials Registry Platform. Relevant trial entries of drugs or plasma were downloaded on 26 March 2020, deduplicated, verified with reviews of major medical journals and WHO websites and independently analysed by two reviewers.

Main outcome(s) Trial intervention, sponsorship, critical design elements and specified outcomes

Results Overall, 201 clinical trials were registered for testing the therapeutic benefits of 92 drugs or plasma, including 64 in monotherapy and 28 different combinations. Only eight (8.7\%) products or combinations involved new molecular entities. The other test therapies had a wide range of prior medical uses, including as antivirals, antimalarials, immunosuppressants and oncology treatments. In 152 trials (75.7\%), patients were randomised to treatment or comparator, including 55 trials with some form of blinding and 97 open-label studies. The 49 (24.4\%) of trials without a randomised design included 29 single armed studies and 20 trials with some comparison group. Most trial designs featured multiple endpoints. Clinical endpoints were identified in 134 (66.7\%) of trials and included COVID-19 symptoms, death, recovery, required intensive care and hospital discharge. Clinical scales were being used in 33 (16.4\%) trials, most often measures of oxygenation and critical illness. Surrogate endpoints or biomarkers were studied in $88(42.3 \%)$ of trials, primarily assays of viral load. Although the trials were initiated in more than 17 countries or regions, $100(49.8 \%)$ were registered in China and 78 (37.8\%) in the USA. Registered trials increased rapidly, with the number of registered trials doubling from 1 March to 26 March 2020

Conclusions While accelerating morbidity and mortality from the COVID-19 pandemic has been paralleled by early and rapid clinical investigation, many trials lack features to optimise their scientific value. Global coordination and increased funding of high-quality research may help to maximise scientific progress in rapidly discovering safe and effective treatments.

\section{Strengths and limitations of this study}

- We comprehensively assessed the WHO's clinical trials registry network and US clinical trials to identify early clinical trials examining COVID-19 treatments.

- In addition to identifying investigational therapies, we also characterised the sponsorship, critical design elements and specified outcomes of each registered clinical trial.

- We also report the pharmacological mechanisms and clinical uses for drugs under investigation.

- Our analyses was limited to clinical trials of drugs or plasma, and many additional trials have been registered since our analysis was performed.

\section{INTRODUCTION}

Since its identification in China in late 2019, the epidemic of severe acute respiratory syndrome coronavirus 2 (SARS-CoV-2) has spread rapidly, with all countries and territories reporting cases by April 2020. ${ }^{1}$ Although knowledge of the coronavirus disease 2019 (COVID-19) pandemic's true epidemiology has been constrained by the limited availability of testing and surveillance, as of 4 June 2020 , over 6 million cases had been confirmed around the world, with over 380000 deaths. ${ }^{2}$

The impact of the pandemic, as well as uncertainty regarding its future course, has unleashed a wave of biomedical research to identify safe and effective treatments for COVID-19. While new molecular entities are under investigation, many therapies previously approved by regulators for the treatment of other diseases are also being evaluated for repurposing for viral suppression or for lessening the inflammatory consequences of infection. ${ }^{3}$ There is also interest in assessing the use of convalescent plasma to treat COVID-19. ${ }^{4}$

Both media ${ }^{5}$ and industry, ${ }^{6} 7$ reports have characterised products being assessed for therapeutic activity against COVID-19. We sought to complement these with a rigorous 


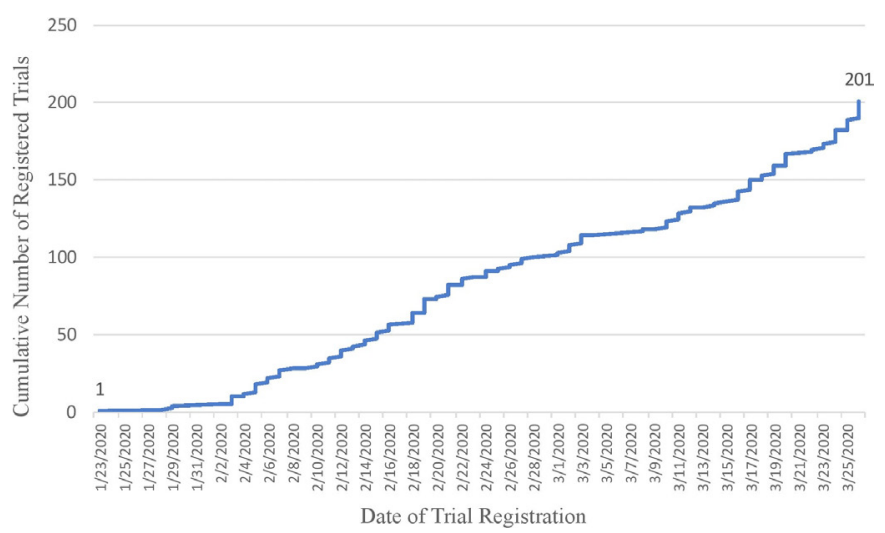

Figure 1 Cumulative number of registered clinical trials of products for SARS-CoV-2 infection. Sources: WHO and ClinicalTrials.gov (as of 26 March 2020). SARS-CoV-2, severe acute respiratory syndrome coronavirus 2 .

appraisal of early efforts around the world to identify safe and efficacious treatments to address the pandemic. In addition to identifying investigational therapies, we also characterised the sponsorship, critical design elements and specified outcomes of each registered clinical trial. While our analysis represents an early snapshot of a continually evolving area, it nevertheless provides timely and globally important information for researchers, policy makers and the general public.

\section{METHODS}

\section{Data sources}

We used information from the WHO's clinical trials registry network and ClinicalTrials.gov. ClinicalTrials. gov is a registry of public and privately funded clinical trials conducted around the world maintained by the US National Library of Medicine on behalf of the National Institutes of Medicine. The WHO registry network includes clinical trials from countries including Australia, Brazil, China, South Korea, India, Cuba, European Union, Germany, Iran, Japan, Lebanon, Thailand, Netherlands, Pan Africa, Peru, Sri Lanka and the UK. Each participating country sends their data to the International Clinical Trials Registry Platform (ICTRP) maintained by the WHO. ${ }^{8}$ Both the WHO registry ${ }^{9}$ and ClinicalTrials. gov $^{10}$ require that registered trials meet specific criteria for content, quality and validity, accessibility, unique identification, technical capacity and administration, and requirements of the International Committee of Medical Journal Editors.

\section{Registry searches}

We downloaded all COVID-19 trials provided by the WHO in a Microsoft Excel spreadsheet. ${ }^{11}$ The WHO curated all COVID-19 trials published on the ICTRP database in an Excel file. Therefore, no search strategy was applied to the ICTRP database. We also performed a manual search of each of the WHO's 17 network registries, such as EU Clinical trials register to identify additional trials, yielding 21 additional studies. We combined these data with information from the ClincialTrials.gov registry. ${ }^{12}$ All searches were last updated on 26 March 2020. To identify trials registered in the USA, we searched the ClinicalTrials.gov registry for trials related to the 2019 novel coronavirus using keywords 'Coronavirus' or 'COVID19' or 'COVID19' or '2019 novel coronavirus' or '2019nCoV' or 'SARS-CoV-2' (online supplementary eTable 1). In order to assess whether there were omitted trials, we also searched major medical journals, such as Lancet, New England Journal of Medicine and JAMA, and websites from the WHO, US Centers for Disease Control and Prevention and media aggregators. These searches did not reveal any additional trials to be included in the analysis.

For each product that was approved by regulators, we searched for information from the European Medicines Agency (EMA) ${ }^{13}$ and US Food and Drug Administration $(\mathrm{FDA})^{14}$ describing mechanisms of action and approved indications. We searched the pharmaceutical manufacturers' websites and other online sources for information about drugs that were not approved in the European Union or the USA.

\section{Trial selection}

We included all studies conducted on patients diagnosed with COVID-19. First, we selected interventional clinical trials based on the 'study type' variable (online supplementary eFigure 1). This variable contains values such as interventional trials, observational studies, expanded access, diagnostic test, basic science, prevention, prognosis, epidemiological research, health services research and screening. Interventional studies are 'studies that prospectively assign human participants or groups of

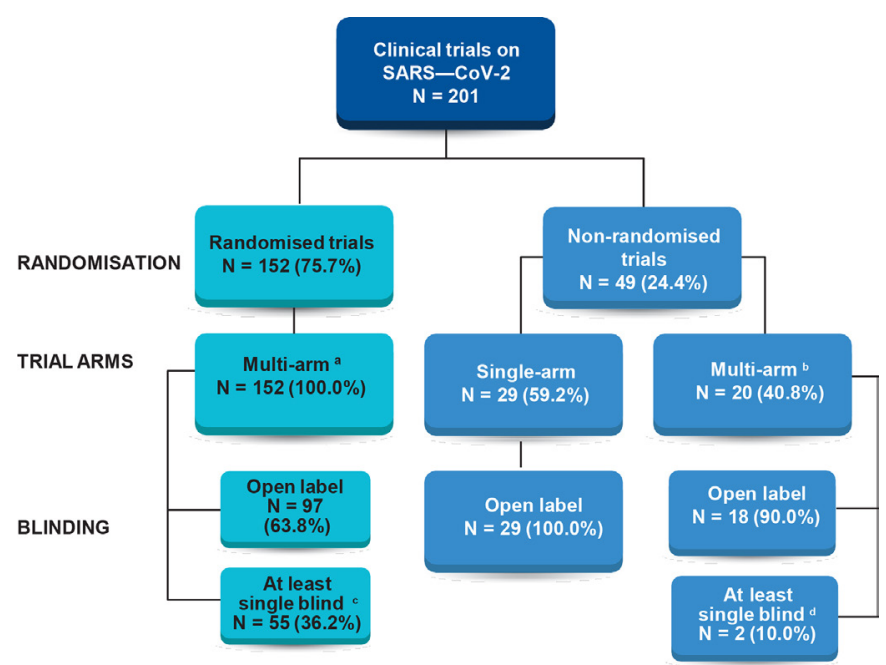

Figure 2 Study designs of registered clinical trials of products for SARS-CoV-2 infection ( $\mathrm{n}=201$ trials). ${ }^{\text {Includes }}$ 147 parallel, 1 platform and 4 sequential trials; ${ }^{b}$ includes 1 crossover, 1 factorial, 17 parallel and 1 historical control arm trials; 'includes 14 single, 5 at least single, 16 double, 2 triple and 18 quadruple blinded trials; ${ }^{d i n c l u d e s ~ t w o ~ d o u b l e-b l i n d ~}$ trials. Sources: WHO and ClinicalTrials.gov (as of 26 March 2020). SARS-CoV-2, severe acute respiratory syndrome coronavirus 2. 
Table 1 Characteristics of registered clinical trials for SARS-CoV-2 infection ( $n=201$ trials)

\begin{tabular}{|c|c|}
\hline Clinical trial characteristics & Total trials $(n=201)$ \\
\hline \multicolumn{2}{|l|}{ Trial intervention, $\mathrm{n}(\%)$} \\
\hline Drug & $188(93.5)$ \\
\hline Plasma & $13(6.5)$ \\
\hline \multicolumn{2}{|l|}{ Trial registry source, n (\%) } \\
\hline China & $100(49.8)$ \\
\hline USA & $76(37.8)$ \\
\hline Europe Union & $9(4.5)$ \\
\hline Iran & $10(5.0)$ \\
\hline Japan & $4(2.0)$ \\
\hline ISRCTN & $2(1.0)$ \\
\hline \multicolumn{2}{|l|}{ Status, $n(\%)$} \\
\hline Recruiting & $120(59.7)$ \\
\hline Not yet recruiting & $75(37.3)$ \\
\hline Withdrawn & $6(3.0)$ \\
\hline \multicolumn{2}{|l|}{ Recruitment country, ${ }^{*} \mathrm{n}(\%)$} \\
\hline China & $126(53.9)$ \\
\hline Europe & $31(13.3)$ \\
\hline Asia (except China) & $18(7.7)$ \\
\hline North America & $17(7.3)$ \\
\hline Middle East & $13(5.6)$ \\
\hline South America & $6(2.6)$ \\
\hline Africa & $1(0.4)$ \\
\hline Not reported & $22(9.4)$ \\
\hline \multicolumn{2}{|l|}{ Phase, n (\%) } \\
\hline 0 & $37(18.4)$ \\
\hline 1 or $1 / 2$ & $5(2.5)$ \\
\hline 2 & $32(15.9)$ \\
\hline $2 / 3$ & $16(8.0)$ \\
\hline 3 & $33(16.4)$ \\
\hline 4 & $51(24.9)$ \\
\hline Not applicable & $26(12.9)$ \\
\hline Missing & $2(1.0)$ \\
\hline \multicolumn{2}{|l|}{ Lead sponsor, n (\%) } \\
\hline Hospitals & $111(55.2)$ \\
\hline Industry & $36(17.9)$ \\
\hline Government & $39(19.4)$ \\
\hline Othert & $7(3.5)$ \\
\hline Not reported & $8(4.0)$ \\
\hline \multicolumn{2}{|l|}{ Anticipated enrolment, $\mathrm{n}(\%)$} \\
\hline Median (IQR) & $100(50-240)$ \\
\hline$\leq 50$ & $54(26.9)$ \\
\hline $51-100$ & $53(26.4)$ \\
\hline$\geq 100$ & $94(46.8)$ \\
\hline \multicolumn{2}{|l|}{ Outcome, ${ }^{*} \mathrm{n}(\%)$} \\
\hline Surrogate/biomarker & 85 (42.3) \\
\hline Clinical scale & $33(16.4)$ \\
\hline Clinical outcome & $134(66.7)$ \\
\hline
\end{tabular}

Continued

\section{Table 1 Continued}

Clinical trial characteristics

Total trials $(n=201)$

Sources: WHO and ClinicalTrials.gov (as of 26 March 2020).

*Percentages may exceed $100 \%$ as categories are not mutually exclusive.

tIncludes foundations and disease trial networks.

ISRCTN, International Standard Randomised Controlled Trial Number; SARS-CoV-2, severe acute respiratory syndrome coronavirus 2 .

humans to one or more health-related interventions to evaluate the effects on health outcomes'. ${ }^{15}$ To be inclusive of all trials on drugs and plasma, we did not limit our inclusion criteria to randomised trials. Second, we included studies where drugs or plasma was the primary intervention. Since there was not standardised information about the components of each intervention, two individuals (KM, MT or HM) independently reviewed each interventional study to identify any trials of a drug or plasma. Any disagreement was resolved by a third reviewer (GCA). Because study focus was on evaluating drugs or plasma treatments, we excluded trials of stem cell transplants, devices, diagnostic tests, traditional Chinese medicines/herbal medicine, rehabilitation, dietary supplements and psychological interventions. We did not limit any studies based on the outcomes they evaluated. We also excluded one trial with implausible information regarding its study design (a single-arm randomised controlled trial).

\section{Data extraction and management}

We extracted the following information from each trial: unique trial number, trial registry source (WHO network registry country or the USA), registration date, recruitment status (recruiting, not yet recruiting, withdrawn or cancelled), recruitment country, phase $(0,1,2,3$, 4, 1-2, 2-3, not applicable and missing), anticipated enrolment, lead sponsor, allocation status (randomised or non-randomised), intervention model (single arm, parallel, cross-over, factorial, platform trial or sequential), blinding (open, single, double, triple or quadruple), primary outcome (surrogate/biomarker, clinical scale and clinical outcome) and a website address. Trials that reported recruitment status of completed, active or enrolling by invitation were grouped as recruiting. We used the country address of each facility (ie, a site that can potentially enrol participants) to identify recruitment countries. Enrolment number reflects the estimated total number of participants to be enrolled or the actual total number of participants enrolled.

We used the primary sponsor and collaborators fields from the US registry and primary and secondary sponsor fields from the WHO registry to identify the probable lead sponsor. We classified sponsorship as follows: (1) the lead sponsor was considered to be a pharmaceutical company if the primary sponsor was a pharmaceutical company, or a known funding body like the National Institutes of Health was neither a primary sponsor or collaborators/ secondary sponsor, and at least one collaborator was a pharmaceutical company; (2) the lead sponsor was a 
Table 2 Products being assessed in registered clinical trials for SARS-CoV-2 infection

\begin{tabular}{|c|c|c|c|}
\hline Major drug class and drugs & $\begin{array}{l}\text { Registered } \\
\text { trials, } \mathbf{N}^{*}\end{array}$ & Pharmacological mechanism & Clinical uses \\
\hline Antimalarials & 50 & & \\
\hline Chloroquine or hydroxychloroquine & 49 & $\begin{array}{l}\text { Inhibit certain enzymes by interacting with DNA; } \\
\text { possible antiviral effect on SARS-CoV through } \\
\text { changing the glycosylation of ACE2 receptor and } \\
\text { spike protein. }\end{array}$ & $\begin{array}{l}\text { Malaria, extraintestinal amebiasis, lupus } \\
\text { erythematosus and rheumatoid arthritis. }\end{array}$ \\
\hline Dihydroartemisinin/piperaquine & 1 & $\begin{array}{l}\text { Blocks a step in Plasmodium falciparum } \\
\text { parasite's metabolism needed for its survival. }\end{array}$ & Malaria. \\
\hline
\end{tabular}

\begin{tabular}{lr}
\hline Antivirals $\dagger$ & 67 \\
\hline Asc09/ritonavir & 2 \\
\hline Azvudine & 4 \\
\hline Baloxavir & 2 \\
\hline Danoprevir/ritonavir & 4 \\
\hline
\end{tabular}

\begin{tabular}{|c|c|c|c|}
\hline Darunavir/cobicistat & 1 & $\begin{array}{l}\text { Darunavir inhibits HIV-1 protease enzyme, thus } \\
\text { slowing down multiplication of HIV. }\end{array}$ & HIV-1. \\
\hline Favipiravir & 11 & $\begin{array}{l}\text { Inhibits RNA polymerase and prevents replication } \\
\text { of the viral genome. }\end{array}$ & Influenza (Japan). \\
\hline Remdesivir & 10 & $\begin{array}{l}\text { Nucleoside analogue; inhibit the action of RNA } \\
\text { polymerase; tested for Ebola, MERS and SARS. }\end{array}$ & None; investigational medicine. \\
\hline Oseltamivir & 2 & $\begin{array}{l}\text { Inhibitor of influenza virus neuraminidase } \\
\text { affecting release of viral particles. }\end{array}$ & Influenza. \\
\hline Umifenovir & 6 & Inhibits membrane fusion in influenza virus. & Influenza (Russia and China). \\
\hline Sofosbuvir/ledipasvir & 1 & $\begin{array}{l}\text { Sofosbuvir inhibits HCV NS5B RNA; ledipasvir } \\
\text { inhibits HCV NS5A inhibitor. }\end{array}$ & Hepatitis C. \\
\hline
\end{tabular}

\begin{tabular}{lr} 
Different antiviral combinations $\ddagger$ & 7 \\
\hline Immunosuppressants & 27
\end{tabular}

Adalimumab 1

HIV-1 protease inhibitor.

Investigational drug for HIV (China).

Reverse transcriptase inhibitor.

Investigational drug for HIV-1. Polymerase acidic (PA) endonuclease inhibitor. Influenza.

Danoprevir inhibits hepatitis virus C NS3/4A Investigational drug for hepatitis C. protease inhibitor.

inhibits HCV NS5A inhibitor.

\begin{tabular}{|c|c|c|c|}
\hline Baricitinib & 2 & Janus kinase inhibitor. & Rheumatoid arthritis. \\
\hline Fingolimod & 1 & Sphingosine 1-phosphate receptor modulator. & Multiple sclerosis. \\
\hline Ixekizumab & 1 & Interleukin-17A antagonist. & Plaque psoriasis and psoriatic arthritis. \\
\hline Pirfenidone & 3 & Not yet known; reduce fibroblasts production. & Idiopathic pulmonary fibrosis. \\
\hline Sarilumab & 4 & Interleukin-6 receptor antagonist. & Rheumatoid arthritis. \\
\hline Tocilizumab & 11 & Interleukin-6 receptor antagonist. & $\begin{array}{l}\text { Rheumatoid arthritis, giant cell arteritis, } \\
\text { juvenile idiopathic arthritis and cytokine } \\
\text { release syndrome. }\end{array}$ \\
\hline Immunostimulants & 16 & & \\
\hline Interferon & 15 & Recombinant cytokine with antiviral properties. & $\begin{array}{l}\text { Hepatitis B, hepatitis C, leukaemia, } \\
\text { multiple myeloma, follicular lymphoma, } \\
\text { carcinoid tumour and malignant } \\
\text { melanoma. }\end{array}$ \\
\hline Anticancer drugs & 7 & & \\
\hline Bevacizumab & 2 & $\begin{array}{l}\text { Vascular endothelial growth factor-specific } \\
\text { angiogenesis inhibitor. }\end{array}$ & $\begin{array}{l}\text { Several types of cancer; for example, } \\
\text { colon, lung and breast. }\end{array}$ \\
\hline
\end{tabular}

Blocks tumour necrosis factor- $\alpha$, thereby reducing inflammation and other symptoms of the disease.

Janus kinase inhibitor.

Sphingosine 1-phosphate receptor modulator.

Interleukin-17A antagonist.

Not yet known; reduce fibroblasts production inflammatory and antiangiogenic properties.

Continued
Rheumatoid arthritis, psoriatic arthritis juvenile idiopathic arthritis, Crohn's disease, axial spondyloarthritis and plaque psoriasis.

Plaque psoriasis and psoriatic arthritis. arthritis.

ary fibrosis.

Multiple myeloma and erythema

Rheumatoid arthritis, giant cell arteritis, juvenile idiopathic arthritis and cytokine 
Table 2 Continued

\begin{tabular}{|c|c|c|c|}
\hline Major drug class and drugs & $\begin{array}{l}\text { Registered } \\
\text { trials, } \mathbf{N}^{\star}\end{array}$ & Pharmacological mechanism & Clinical uses \\
\hline Colchicine & 2 & Tubulin disruption. & $\begin{array}{l}\text { Gout flare and familial Mediterranean } \\
\text { fever. }\end{array}$ \\
\hline Ruxolitinib & 1 & Janus kinases inhibitor. & Myelofibrosis and polycythaemia vera. \\
\hline Dexamethasone & 1 & Apoptosis of multiple myeloma cells. & Multiple myeloma. \\
\hline Methylprednisolone & 5 & $\begin{array}{l}\text { Binds to nuclear receptors to dampen } \\
\text { proinflammatory cytokines. }\end{array}$ & $\begin{array}{l}\text { Several uses; for example, endocrine, } \\
\text { rheumatic and collagen disorders. }\end{array}$ \\
\hline Immunoglobulins & 3 & & $\begin{array}{l}\text { Several autoimmune, infectious and } \\
\text { idiopathic diseases. }\end{array}$ \\
\hline Antifibrinolytics (proteinase inhibitors) & 2 & & \\
\hline Camostat & 1 & Serine protease inhibitor. & $\begin{array}{l}\text { Chronic pancreatitis and postoperative } \\
\text { reflux esophagitis (Japan). }\end{array}$ \\
\hline Ulinastat & 1 & Urinary trypsin inhibitor. & Acute pancreatitis and shock (Japan). \\
\hline Expectorants (mucolytics) & 2 & & \\
\hline Acetylcysteine & 1 & Mucolytic agent. & $\begin{array}{l}\text { Abnormal, viscid or inspissated mucous } \\
\text { secretions. }\end{array}$ \\
\hline Bromhexine & 1 & Mucolytic agent. & Congestion and cough. \\
\hline Other drugs & 35 & & \\
\hline Aviptadil & 1 & Analogue of vasoactive intestinal polypeptide. & $\begin{array}{l}\text { Acute lung injury and sarcoidosis } \\
\text { (Europe). }\end{array}$ \\
\hline Dexmedetomidine & 1 & Selective alpha2-adrenergic agonist. & Sedation. \\
\hline Escin & 2 & $\begin{array}{l}\text { Inhibition of an inflammatory response at cellular } \\
\text { level. }\end{array}$ & $\begin{array}{l}\text { Decongestant and reduction of swelling } \\
\text { following injuries. }\end{array}$ \\
\hline GD31 (nucleoside analogue) & 1 & Nucleoside analogues. & Not found. \\
\hline Jakotinib & 1 & Janus kinase inhibitor. & Investigational drug (China). \\
\hline Losartan & 2 & Angiotensin II receptor blockers. & Hypertension. \\
\hline Meformin & 1 & $\begin{array}{l}\text { Decreases hepatic production and intestinal } \\
\text { absorption of glucose and improves insulin } \\
\text { sensitivity. }\end{array}$ & Diabetes mellitus. \\
\hline Meplazumab & 1 & Humanised anti-CD147 antibody. & Investigational drug. \\
\hline Nitric oxide & 5 & Vasodilating agent. & Hypoxic respiratory failure in neonates. \\
\hline Noscapine & 1 & Opium alkaloid. & Cough suppressant. \\
\hline PUL-042 & 2 & Agonists of Toll-like receptors. & Investigational drug. \\
\hline Polyinosinic-polycytidylic acid & 1 & $\begin{array}{l}\text { Upregulation of antitumor genes and the } \\
\text { induction of cell apoptosis. }\end{array}$ & Possible anticancer activity. \\
\hline Recombinant human ACE2 & 1 & Renin-angiotensin system peptidase. & Possible heart failure therapy. \\
\hline Recombinant human interleukin-2 & 1 & T cell growth factor. & Melanoma and renal cell carcinoma. \\
\hline $\begin{array}{l}\text { Recombinant human granulocyte colony } \\
\text { stimulating factor }\end{array}$ & 1 & Mediating $T$ cell tolerance. & $\begin{array}{l}\text { Neutrophil-mediated inflammatory } \\
\text { disease. }\end{array}$ \\
\hline Sildenafil (urologicals) & 1 & Sigma receptor agonist activity. & Erectile dysfunction. \\
\hline
\end{tabular}


Table 2 Continued

\begin{tabular}{|c|c|c|c|}
\hline Major drug class and drugs & $\begin{array}{l}\text { Registered } \\
\text { trials, } \mathbf{N}^{\star}\end{array}$ & Pharmacological mechanism & Clinical uses \\
\hline Suramin (antiprotozoals) & 1 & Macrofilaricidal. & $\begin{array}{l}\text { African sleeping sickness and river } \\
\text { blindness (Africa). }\end{array}$ \\
\hline Thymosin & 3 & 5Da polypeptide hormone. & Investigational drug for cancer. \\
\hline Tranilast & 1 & $\begin{array}{l}\text { Haematopoietic prostaglandin D synthase } \\
\text { inhibitor. }\end{array}$ & $\begin{array}{l}\text { Bronchial asthma, keloid, hypertrophic } \\
\text { scar and allergic disorders (Japan and } \\
\text { South Korea). }\end{array}$ \\
\hline Antiviral+immunosuppressants $\ddagger$ & 2 & & \\
\hline Antimalarials+antibacterialł & 2 & & \\
\hline Antimalarials+antivirals $\ddagger$ & 10 & & \\
\hline Antivirals+interferon $\ddagger$ & 13 & & \\
\hline
\end{tabular}

*Column total exceeds 202 as some trials examine multiple drugs.

†Ritonavir and cobicistat inhibit CYP3A metabolism and increase blood concentration of the other antiviral drug.

fDetails on drug combinations are provided in table 3.

§One trial did not specify type of corticosteroid.

MERS, Middle East respiratory syndrome; SARS-CoV-2, severe acute respiratory syndrome coronavirus 2.

known government research funding agency if identified as such or at least one collaborator was this funder; (3) the lead sponsor was a hospital if so stated; (4) all others were classifies as other. For some trials, the study design or blinding was unclear. In such cases, two reviewers (HM and SE) independently reviewed the registry record in detail and extracted the information. If, after in-depth review, study design was still unclear $(n=37)$, we used the following rules to assign intervention model and blinding: (1) trials with a single group were considered as non-randomised and open-labeli: ${ }^{17}$ (2) trials that reported more than one group were considered having a parallel group design; and (3) trials were considered open label if blinding was not reported and could not be inferred. We grouped parallel, cross-over, factorial, platform and sequential intervention trials as multiarm ( $>2$ trial arms).

Two reviewers (HM and TM) independently reviewed primary outcomes of all trials and assigned them as surrogate or biomarker, clinical scale or clinical outcomes. Surrogate or biomarker included any measure of SARS-CoV-2 or any blood test; clinical scales included measures of oxygenation, Sequential Organ Failure Assessment score, National Early Warning Score 2 score, lung injury score or any measure of pulmonary harms; and clinical outcomes included symptoms, clinical improvement scores, intubation, hospitalisation or death. Reviewer disagreement was resolved by discussion and consensus.

We identified drugs under investigation for COVID-19 from the experimental and/or control arm of each trial, including multiple drugs when they were studied in combination. Because the trial registries did not record drugs in a standardised format, two pharmacist reviewers (HM and SS) independently extracted this information, converting brand names were scientific names and correcting minor spelling errors. We used the WHO's Anatomical Therapeutic Chemical Classification System to classify drugs in major therapeutic or pharmacological subgroups. For the 18 drugs (eg, remdesivir) that were not included in the WHO's ATC algorithms, we used product information from the EMA, US FDA or the companies' websites to characterise the product.

\section{Analysis}

We used descriptive statistics to analyse the extracted data. We summarised the characteristics of all included trials using frequency and percentages. We listed unique drugs under investigation and the number of registered clinical trials for each product. We plotted the number of cumulative trials by their registration date. All data were extracted and stored in an open-access Google Sheet document (https://docs.google.com/spreadsheets/d/ 1p_229olyi7ft6MCLYXdS4-dkKszjnAiSnLRVO68OLk8/ edit? usp=sharing). We used SAS V.9 for all analyses.

\section{Patient and public involvement}

While we did not directly involve patients in the design or conduct of our investigation, our analyses were motivated by a belief that it is important for patients, and the general public, to have accessible, high-quality information regarding the structure and outcomes of clinical trials assessing therapeutics targeting COVID-19.

\section{RESULTS}

\section{Characteristics of clinical trials}

Overall, 201 clinical trials were registered for testing the therapeutic benefits of 92 drugs or plasma, including 64 in monotherapy and 28 different combinations (table 1). Although the trials were initiated in more than 17 countries or regions, $100(49.8 \%)$ were registered in China and 
$78(37.8 \%)$ were in the USA. Of the 201 trials, $4(2.0 \%)$ were registered in January 2020, 97 (48.2\%) in February and $100(49.8 \%)$ between 1 March and 26 March 2020 (figure 1). Nearly $60 \%$ of the trials were recruiting patients, and more than half were sponsored by hospitals or universities $(55.2 \%)$, while about one in five were sponsored by a government $(19.4 \%)$ and a similar proportion (17.9\%) were industry sponsored.

In 152 trials (75.7\%), patients were randomised to treatment or comparator, including 55 trials with some form of blinding and 97 open-label studies (figure 2). The 49 $(24.4 \%)$ of trials without a randomised design included 29 single armed studies and 20 trials with some comparison group. Of the 201 trials, 54 (26.9\%) were parallel group, randomised controlled trials with at least single blinding.

\section{Primary endpoints}

Most trial designs featured multiple endpoints. Clinical endpoints were identified in $134(66.7 \%)$ of trials and included COVID-19 symptoms, death, recovery, required intensive care and hospital discharge. Clinical scales were being used in $33(16.4 \%)$ trials, most often measures of oxygenation and critical illness assessment instruments. Surrogate endpoints or biomarkers were studied in 88 $(42.3 \%)$ of trials, primarily assays of viral load. None of the trials assessed quality of life as outcome measures.

\section{Study size}

Overall, the studies projected enrolling a median (IQR) of 100 (IQR 50-240) patients. Notably, 54 (26.9\%) of trials sought to enrol 50 or fewer patients. At the other extreme, $94(46.8 \%)$ trials sought to enrol 100 or more patients, with $20(9.6 \%)$ studies anticipating enrolment of 500 or more patients.

\section{Therapies under evaluation}

Overall, 92 drugs or plasma were under investigation, including 64 in monotherapy and 28 different combinations (table 2). Only eight $(8.7 \%)$ products or combinations involved new molecular entities. The other test therapies had a wide range of prior medical uses: 412 $(18.8 \%)$ were antivirals, $9(14.1 \%)$ immunosuppressants other than corticosteroids, 4 anticancer drugs $(6.3 \%), 3$ $(4.7 \%)$ antimalarials, $2(3.1 \%)$ corticosteroids, $2(3.1 \%)$ immunostimulants and $2(3.1 \%)$ antithrombotic agents. The 28 different combinations including antivirals, antimalarials, immunosuppressants, immunostimulants and antibacterials (table 3$)$. Of these, nine $(32 \%)$ were antimalarial/antiviral combinations, seven (25\%) antiviral/ immunosuppressant combination and six (21\%) antiviral/interferon combination.

\section{DISCUSSION}

This study characterised the scope, objectives and content of the current global research programme to find effective therapies for COVID-19 as reported to the leading
Table 3 Drug combinations under investigation for SARSCoV-2 infection ( $\mathrm{n}=28$ combinations)

\begin{tabular}{|c|c|}
\hline & $\begin{array}{l}\text { Registereo } \\
\text { trials, } \mathbf{N}\end{array}$ \\
\hline Different antiviral combinations & 7 \\
\hline Asc09f (Asc09/ritonavir)+oseltamivir & 1 \\
\hline Darunavir/ritonavir+oseltamivir & 1 \\
\hline Favipiravir+lopinavir/ritonavir & 1 \\
\hline Lopinavir/ritonavir+oseltamivir & 1 \\
\hline Lopinavir/ritonavir+emtritabine/tenofovir & 1 \\
\hline Ritonavir+oseltamivir & 1 \\
\hline Sofosbuvir+daclatasvir & 1 \\
\hline \multicolumn{2}{|l|}{ Immunosuppressants combination } \\
\hline Tocilizumab+adamumab & 1 \\
\hline Antiviral+immunosuppressants & 2 \\
\hline Favipiravir+tocilizumab & 2 \\
\hline Antimalarials+antibacterial & 2 \\
\hline Hydroxychloroquine+azithromycin & 2 \\
\hline Antimalarials+antivirals & 10 \\
\hline Darunavir/cobicistat+hydroxychloroquine & 1 \\
\hline Darunavir/ritonavir+favipiravir+chloroquine & 1 \\
\hline Darunavir/ritonavir+oseltamivir+chloroquine & 1 \\
\hline Favipiravir+chloroquine & 2 \\
\hline Hydroxychloroquine+lopinaviror atazanavir/ritonavir & 1 \\
\hline Hydroxychloroquine+oseltamivir+lopinavir+interferon & 1 \\
\hline Lopinavir/ritonavir+chloroquine & 1 \\
\hline Lopinavir/ritonavir+hydroxychloroquine & 1 \\
\hline Oseltamivir+chloroquine & 1 \\
\hline Antivirals+interferon & 13 \\
\hline Asc09/ritonavir+interferon & 1 \\
\hline Favipiravir+interferon & 1 \\
\hline Lopinavir/ritonavir+interferon & 6 \\
\hline Ribavirin+interferon & 2 \\
\hline Ribavirin+lopinavir/ritonavir+interferon & 1 \\
\hline Umifenovir+interferon & 2 \\
\hline Other combinations & 3 \\
\hline Darunavir/cobicistat+thymosin & 1 \\
\hline Lopinavir/ritonavir+thymosin & 1 \\
\hline Ebastine+interferon+lopinavir & 1 \\
\hline
\end{tabular}

Sources: WHO and ClinicalTrials.gov (as of 26 March 2020).

SARS-CoV-2, severe acute respiratory syndrome coronavirus 2 .

clinical trial registries. These data show that the primary focus of clinical trial research at present is to assess whether a wide range of existing therapeutic products might also be effective against acute illnesses caused by the novel SARS-Cov-2 virus. Because one-third of trials exclude clinical endpoints, nearly one half are designed to enrol fewer than 100 patients and two-thirds are open label, many of these studies are likely to yield only preliminary evidence of a given treatment's safety and effectiveness against COVID-19. 
Our results indicate that current scientific activity is concentrated in China and the USA, accounting for $87.6 \%$ of the studies. Some of the products under investigation, such as remdesivir, have considerable preclinical and clinical evidence to support their potential value. In addition to single-site trials, several major, multisite trials of therapies against COVID-19 are also underway. Solidarity, announced by the WHO on 20 March 2020, is a multicentre, adaptive, randomised, open-label, five-arm trial testing remdesivir, chloroquine/hydroxychloroquine, ritonavir/lopinavir and ritonavir/lopinavir with interferon-beta against standard of care in dozens of countries around the globe ${ }^{18}$ Discovery, coordinated by France's National Institute of Health and Medical Research (Inserm), is designed as an add-on trial in Europe and will study the same drugs with the exclusion of chloroquine. ${ }^{19}$ The vast majority of test therapies have been approved for other uses, although eight new molecular entities are being assessed, a number that is likely to grow as governments and industry invest in new compounds during the coming months.

Our findings provide reason for both optimism and caution. Many registered COVID-19 trials have been designed expediently, and while case series and single-arm trials have value and may provide early signals, randomised study designs provide higher quality evidence and will maximise chances for finding effective and safe treatments during this wave of the pandemic. These trial designs, however, need adequate funding as well as scientific leadership, especially as frontline clinicians are tasked with saving lives. In addition, it is important that surrogate outcomes, biomarkers or clinical scales are strongly and directly linked to what matters most for providers and patients-improved chances of recovery from COVID-19. 2021

This study provides early evidence of the benefits of global registries to characterise urgent clinical trial research questions now under investigation. Used wisely by active researchers, these registries can help to identify the most promising avenues for developing new therapies, avoid unnecessary duplication and define unanswered questions that inevitably arise from early research. The registries also constitute a focal point for developing a more comprehensive programme to share protocols and research results. Given the early use of preprints prior to peer review and multiple journals publishing results, the global research enterprise needs to enlarge and extend the cooperative effort initiated by these registries.

\section{Limitations}

Our analysis was limited to a cross-sectional review of trials registered early in the pandemic with one-half the studies registered in the previous month. Many of these studies appeared to be exploratory and not explicitly powered to test a specific drug effect on a prespecified primary endpoint. In addition, our assessment was limited to drugs and plasma, rather than other treatment modalities under investigation. We did not include trials from Health Canada's Clinical Trials Database because this database does not provide relevant details on trial characteristics. However, if trials are reported in US or WHO database, they are included in our study. We did not apply Standard Protocol Items: Recommendations for Interventional Trials guideline to evaluate overall quality of clinical trials protocol. Future research can evaluate quality of clinical trials for COVID-19. Finally, our analysis is only as good as the data that it is based on; the ICTRP gathers information from more than a dozen contributing countries, and despite its value, there remain opportunities to improve the consistency and quality of submitted data from both this platform ${ }^{22}$ and ClinicalTrials.gov. ${ }^{23}$

\section{CONCLUSIONS}

The global pandemic has galvanised the world's research community, and there are signs of remarkable scientific activity. ${ }^{24}$ In this review of clinical trials registered early in course of the pandemic's first wave, we found evidence of rapid clinical investigation of existing antivirals, antimalarials, immunosuppressants and oncology treatments for repurposing against COVID19. Despite this, many registered trials lack features to optimise their scientific value. Global coordination and increased funding of high-quality research may help to maximise scientific progress in rapidly discovering safe and effective treatments.

Acknowledgements The authors gratefully acknowledge Kristin Meek (KM), Matthew Tajanlangit (MT) and Jamie Heyward for assistance extracting information from trial registries and Sneha Sura (SS) for assistance reviewing drug information and data management.

Contributors HM and GCA conceived the study idea. All authors contributed to the study design. HM performed the data collection and analysis. SE and TJM contributed to the data collection. HM and GCA drafted the first version of the manuscript. All authors critically reviewed the manuscript and approved the final version.

Funding The authors have not declared a specific grant for this research from any funding agency in the public, commercial or not-for-profit sectors.

Competing interests GCA is past Chair of Food and Drug Administration's Peripheral and Central Nervous System Advisory Committee; has served as a paid advisor to IQVIA; is a cofounding principal and equity holder in Monument Analytics, a health carehealthcare consultancy whose clients include the life sciences industry as well as plaintiffs in opioid litigation; and is a member of OptumRx's National P\&T Committee. This arrangement has been reviewed and approved by Johns Hopkins University in accordance with its conflict of interest policies.

\section{Patient consent for publication Not required.}

Ethics approval The study was considered non-human subject research by the Johns Hopkins University Institutional Review Board.

Provenance and peer review Not commissioned; externally peer reviewed.

Data availability statement Data are available in a public, open access repository. Data are stored in an open-access Google Sheet document: https://docs.google. com/spreadsheets/d/1p_229olyi7ft6MCLYXdS4-dkKszjnAiSnLRV0680Lk8/edit\# gid $=0$.

Open access This is an open access article distributed in accordance with the Creative Commons Attribution Non Commercial (CC BY-NC 4.0) license, which permits others to distribute, remix, adapt, build upon this work non-commercially, and license their derivative works on different terms, provided the original work is 
properly cited, appropriate credit is given, any changes made indicated, and the use is non-commercial. See: http://creativecommons.org/licenses/by-nc/4.0/.

\section{ORCID iDs}

Hemalkumar B Mehta http://orcid.org/0000-0001-9134-6370

Thomas J Moore http://orcid.org/0000-0003-0994-836X

\section{REFERENCES}

1 World Health Organization. Coronavirus disease (COVID-19) Dashboard. Available: https://covid19.who.int/ [Accessed 4 June 2020].

2 Coronavirus Resource Center. Coronavirus COVID-19 global cases by the center for systems science and engineering. Available: https:// coronavirus.jhu.edu/map.html [Accessed 4 June 2020].

3 Harrison C. Coronavirus puts drug repurposing on the fast track. Nat Biotechnol 2020;38:379-81.

4 Shen $\mathrm{C}$, Wang Z, Zhao F, et al. Treatment of 5 critically ill patients with COVID-19 with convalescent plasma. JAMA 2020;323:1582

5 Zimmer C. Scientists identify 69 drugs to test against the coronavirus: New York times, 2020. Available: https://www.nytimes. com/2020/03/22/science/coronavirus-drugs-chloroquine.html [Accessed 25 Mar 2020].

6 The Milken Institute. COVID-19 treatment and vaccine Tracker. Available: https://milkeninstitute.org/sites/default/files/2020-03/ Covid19-Tracker-3-36-20-FINAL.pdf [Accessed 25 Mar 2020].

7 Garde D. An updated guide to the coronavirus drugs and vaccines in development. Available: https://www.statnews.com/2020/03/ 19/an-updated-guide-to-the-coronavirus-drugs-and-vaccines-indevelopment/ [Accessed 26 Mar 2020].

8 World Health Organization. International clinical trials registry platform (ICTRP). Available: https://www.who.int/ictrp/network/ primary/en/ [Accessed 26 Mar 2020].

9 World Health Organization. International clinical trials registry platform (ICTRP). Available: https://www.who.int/ictrp/network/trds/ en/ [Accessed 25 Mar 2020].

10 ClinicalTrials.gov. Protocol registration data element definitions for interventional and observational studies. National library of medicine.
Available: https://prsinfo.clinicaltrials.gov/definitions.html [Accessed 25 Mar 2020].

11 World Health Organization. WHO database of COVID-19 trials. Available: who.int/ictrp/en/ [Accessed 25 Mar 2020].

12 ClinicalTrials.gov. National library of medicine. Available: www. clinicaltrials.gov [Accessed 25 Mar 2020].

13 European Medicines Agency. European medicines regulatory network fully mobilised in fight against COVID-19. Available: https:// www.ema.europa.eu/en [Accessed 25 Mar 2020].

14 U.S. Food and Drug Administration. Coronavirus disease 2019 (COVID-19). Available: FDA.gov [Accessed 25 Mar 2020].

15 World Health Organization. International standards for clinical trial registries. Available: https://apps.who.int/iris/bitstream/handle/ 10665/76705/9789241504294_eng.pdf;jsessionid=719FA2FAFABC E205F4CD68277AD9FEAD?sequence=1 [Accessed 25 Mar 2020].

16 ClinicalTrials.gov. Protocol registration data element definitions for interventional and observational studies, 2019. Available: https:// prsinfo.clinicaltrials.gov/definitions.html [Accessed 25 Mar 2020].

17 Califf RM, Zarin DA, Kramer JM, et al. Characteristics of clinical trials registered in ClinicalTrials.gov, 2007-2010. JAMA 2012;307:1838-47.

18 UN News. UN health chief announces global 'solidarity trial' to jumpstart search for COVID-19 treatment, 2020. Available: https:// news.un.org/en/story/2020/03/1059722 [Accessed 3 Apr 2020].

19 Kupferschmidt K, Cohen J. WHO launches global megatrial of the four most promising coronavirus treatments. Science 2020.

20 Selleck MJ, Senthil M, Wall NR. Making meaningful clinical use of biomarkers. Biomark Insights 2017;12:1177271917715236.

21 Pletcher MJ, Pignone M. Evaluating the clinical utility of a biomarker: a review of methods for estimating health impact. Circulation 2011;123:1116-24.

22 Viergever RF, Karam G, Reis A, et al. The quality of registration of clinical trials: still a problem. PLoS One 2014;9:e84727.

23 Tse T, Fain KM, Zarin DA. How to avoid common problems when using clinicaltrials.gov in research: 10 issues to consider. BMJ 2018;361:k1452.

24 Apuzzo M, Kirkpatrick DD. Covid-19 changed how the world does science, together: New York times, 2020. Available: https://www. nytimes.com/2020/04/01/world/europe/coronavirus-scienceresearch-cooperation.html [Accessed 1 Apr 2020]. 